\title{
ESCOLARIZAC̣ÃO DOS FILHOS ENTRE FAMÍLIAS NEGRAS, MESTIÇAS E BRANCAS DO POVOADO DE GOIABEIRAS/MG
}

\begin{abstract}
Alexandra Resende Campos*
RESUMO: Este artigo apresenta os resultados de um estudo comparativo sobre as práticas de escolarização empreendidas por famílias negras, mestiças e brancas do povoado de Goiabeiras (MG) e que possuem filhos em idade escolar. O objetivo foi verificar se tais práticas se diferenciam de acordo com o pertencimento racial das famílias pesquisadas. Dialogamos com autores do campo da Sociologia da Educação que estudaram a relação família-escola, de um lado, e a relação educação e relações raciais, de outro. $\mathrm{Na}$ investigação, foram utilizados instrumentos com características etnográficas. Os resultados indicaram que as distinções existentes entre as práticas de escolarização empreendidas pelas famílias podem ser explicadas não pela dimensão de raça, mas por um conjunto de circunstâncias atuantes presentes na dinâmica das famílias.

Palavras-chave: Raça e Escolarização. Relação Família-Escola. Práticas de Escolarização na Família.

\section{SCHOOLING OF CHILDREN FROM BLACK, MIXED RACE AND WHITE FAMILIES, OF GOIABEIRAS - MG}

ABSTRACT: This paper presents the results of a comparative study on the practices of schooling chosen by Black, Mixed, and White families from Goiabeiras village (MG) that have children of school age. The aim was to verify whether these practices were different according to the racial background of the researched families. We held dialogues with Sociology of Education authors that studied the school-family relationship, on the one hand, and the school's race-relations, on the other. For this investigation, instruments were used that have ethnographic features. Results indicate that the existing distinctions between the practices of schooling chosen by the families cannot be explained simply by the race dimension, but rather by a set of circumstances, present in the dynamics surrounding the families studied.
\end{abstract}

Keywords: Race and Schooling. School-Family Relationship. Schooling Practices in Families.

* Doutoranda em Educação pela Universidade Federal Fluminense (UFF). E-mail: xandinhacampos@yahoo.com.br 


\section{Introdução}

O presente artigo é fruto dos resultados da pesquisa "As práticas de escolarização de famílias rurais: um estudo comparativo entre famílias negras, mestiças e brancas do povoado de Goiabeiras, São João DelRei, MG"', cujos resultados foram apresentados em dissertação de mestrado. O objetivo desta pesquisa consistiu em realizar um estudo comparativo sobre as práticas de escolarização ${ }^{2}$ empreendidas por algumas famílias negras, mestiças e brancas que habitam o povoado de Goiabeiras ${ }^{3}$ e que possuem filhos em idade escolar.

O tema me despertou a atenção quando de minha participação, como bolsista de iniciação científica do Conselho Nacional de Desenvolvimento Científico e Tecnológico (CNPq), em pesquisa sobre as práticas de escolarização das famílias que possuíam filhos matriculados na Escola Municipal de Goiabeiras ${ }^{4}$. A referida pesquisa consistiu de três momentos distintos, porém complementares. No primeiro, construímos o perfil socioeconômico-cultural de 44 famílias que possuíam filhos matriculados na Escola Municipal de Goiabeiras. No segundo momento, traçamos as práticas de escolarização de 15 famílias. A última etapa da pesquisa teve como foco principal a escola, trabalhando tanto com a equipe pedagógica quanto com os discentes, analisando as expectativas e os resultados obtidos pelos alunos.

Do contato estabelecido com os moradores de Goiabeiras, verificamos uma quantidade significativa de famílias negras residentes no povoado. Inclusive, era notória, nas festas religiosas e escolares, a presença de grande número de crianças negras. Com o desenrolar da pesquisa, observamos que a concentração de famílias negras no local não era somente mais uma característica do povoado e, sim, um dado merecedor de ser investigado, uma vez que as condições materiais nesses lares pareciam mais precárias que nos demais, de famílias brancas. Em algumas dessas casas não havia filtro para água, fogão a gás, geladeira, televisão a cores, entre outros equipamentos básicos que garantem condições mínimas de saúde e bem-estar.

Assim, verificamos que Goiabeiras - um povoado rural aparentemente homogêneo, no qual os moradores parecem compartilhar as mesmas redes de relações socioculturais e onde a situação ocupacional, entre os membros das famílias, não se distingue significativamente - apresenta- 
va características distintas segundo o pertencimento racial. Foi a partir desse primeiro estranhamento que me propus realizar a pesquisa de mestrado citada anteriormente.

\section{População negra e educação}

$\mathrm{Na}$ visão de autores como Alves et al. (2007), Henriques (2002) e Soares e Alves (2003), o fenômeno das desigualdades escolares no Brasil vai além do pertencimento de classe. Ainda que os negros ocupem posição social privilegiada, eles sofrem desvantagens frente aos brancos dessa mesma posição; ou seja, as disparidades prevalecem dentro do mesmo contexto social: o negro pobre sofre desvantagens frente ao branco pobre.

Por outro lado, pesquisas realizadas no contexto americano (LAREAU, 2007; CLARK, 1983) têm apontado que o pertencimento racial não apresenta influências no processo de escolarização de crianças negras e brancas 5 . A antropóloga Annette Lareau (2007), ao estudar as práticas que famílias brancas e negras empreendem na educação de seus filhos, verificou que o fator diferenciador de tais práticas não está ligado ao pertencimento racial e, sim, à classe social. A autora realizou uma pesquisa etnográfica com 12 famílias: seis brancas e seis negras, distribuídas igualmente entre as diferentes classes sociais (pobre, classe trabalhadora e classe média). Como resultado de sua pesquisa, ela afirma que:

[...] o papel da raça na vida diária das crianças foi menos importante do que esperávamos [...] os pais brancos e negros de classe média utilizavam-se de práticas similares e muitas vezes idênticas. Um padrão parecido foi observado nas famílias trabalhadoras brancas e negras, assim como nas famílias pobres brancas e negras (LAREAU, 2007, p. 74).

Lareau (2007) aponta que são as famílias de classe média que se aproximam mais da escola, independentemente de serem brancas ou negras, ao passo que as famílias pobres e trabalhadoras mostram-se resistentes a esse tipo de relação. Nas reuniões escolares, os pais de famílias pobres e trabalhadoras se sentem intimidados a levantar dúvidas e questões para os professores. A falta de posicionamento diante dos agentes educativos, além de patentear um sentimento de inutilidade por parte des- 
ses pais, demonstra certa resistência em compartilhar com os professores possíveis problemas que os filhos venham a encontrar na escola:

Por vezes, esses pais encorajam os filhos a resistirem à autoridade da escola. A família Yanelli disse a Billy para bater em um garoto que o estava incomodando. A mãe de Wendy Driver a aconselhou a esmurrar um colega que puxava seu rabo-de-cavalo (LAREAU, 2007, p. 66).

No que se refere à realidade brasileira, Alves et al. (2007) analisaram os dados do Sistema de Avaliação da Educação Básica (SAEB)/2001 referentes a alunos da oitava série, tendo por objetivo apresentar a associação entre repetência escolar e características familiares, levando em consideração o pertencimento racial dos alunos. Segundo esses autores, é possível afirmar que o efeito do capital econômico não opera do mesmo modo no processo de escolarização de famílias pertencentes a diferentes grupos raciais: "[...] Os alunos pretos apresentam maior chance de repetência do que os alunos brancos com o mesmo nível de posse de bens econômicos" (ALVES et al., 2007, p. 177). Tal argumento também se aplica quando esses pesquisadores consideram a variável "capital cultural".

Esses autores constataram, também, que a porcentagem de alunos que fazem os deveres escolares e contam com a colaboração dos pais é maior entre os brancos do que entre os negros. É a população negra que estuda, majoritariamente, em escola pública, que dispõe de poucos recursos culturais e materiais e de um contexto menos favorável e estimulante ao aprendizado escolar.

Sendo a posse de capital econômico e cultural um dos fatores importantes para amenizar a repetência escolar, pode-se pensar que os negros são as principais vítimas desse fenômeno, pois, como mostram os dados dos estudos produzidos pelo Instituto de Pesquisa Econômica Aplicada (IPEA) - Retrato das Desigualdades de Gênero e Raça 2008, pela Pesquisa Nacional por Amostra de Domicílio (PNAD) - Síntese de Indicadores Sociais 2010, por Garcia (2007), Henriques (2002), entre outros, os negros são maioria entre os desempregados, os analfabetos, a população pobre do país, os que ocupam os piores postos no mercado de trabalho, etc.

Acrescente-se a esse quadro o papel das famílias. Para Soares e Alves (2003) e Alves et al. (2007), um dos indicadores de desfavorecimen- 
to dos negros são as características da escola e do ambiente familiar. Como as estatísticas apontam que a população branca apresenta nível de escolaridade maior que a dos negros, entende-se que as famílias brancas se sentem autorizadas e têm condições intelectuais de ajudar os filhos nas tarefas escolares. Nesse sentido, pode-se avaliar o peso do envolvimento familiar no processo de escolarização de crianças negras e brancas.

Alguns estudos na área da Sociologia da Educação - como os de Bressoux (2003), Charlot (2000), Lahire (2008), Portes (2000), entre outros - vêm demonstrando que o fator "classe social" não é determinante para definir a trajetória escolar de um sujeito. Além do peso da posse de capitais (cultural, econômico e social, nos termos de Pierre Bourdieu), há uma série de fatores e circunstâncias atuantes que pode influenciar positivamente no processo de escolarização e na trajetória escolar dos diferentes sujeitos, sejam eles pertencentes a classes privilegiadas ou não. Lahire (2008) e Portes (2000) apontam, entre essas circunstâncias, a presença da ordem moral doméstica; a atenção dos pais com o trabalho escolar dos filhos; a presença do outro na vida do estudante; a ajuda material; a existência de um duradouro grupo de apoio construído no interior do estabelecimento escolar; as formas familiares de cultura escrita; um esforço para compreender e apoiar o filho, etc.

Por essa vertente, é possível acreditar na mobilização dos atores sociais, no caso as famílias, no sentido de propiciar situações de favorecimento para o processo de escolarização de seus filhos. Há famílias populares que, mesmo desprovidas de capital econômico, adotam estratégias no sentido de assegurar aos filhos uma escolarização menos árdua e desigual se comparada à dos filhos pertencentes a classes médias ou elites (ALMEIDA, 2007; LACERDA, 2006; PAIXÃO, 2005; PIOT'TO, 2008, PORTES, 2000; VIANA, 2000, entre outros).

Considerando a situação de desfavorecimento social em que se encontra a população negra no Brasil e dialogando com alguns autores do campo da Sociologia da Educação, sobretudo aqueles que abordam a relação família-escola (LAHIRE, 1998; PAIXÃO, 2005; PIOTTO, 2008, PORTES, 2000 e VIANA, 2000) uma questão foi norteadora para o desenvolvimento da pesquisa junto às famílias do povoado de Goiabeiras: as práticas de escolarização que essas famílias empreendem para manter seus filhos na escola se diferenciam de acordo com o pertencimento racial, por determinadas circunstâncias internas presentes na dinâmica das 
famílias ou devido a pequenas variações entre as famílias, no que se refere à posse de capital cultural, econômico ou social?

\section{0 povoado de Goiabeiras e a pesquisa com as famílias}

Situar Goiabeiras geograficamente nos remonta ao passado de exploração de ouro e pedras preciosas nas Minas Gerais, pois o povoado se encontra em um dos trechos do Caminho Velho da Estrada Real ${ }^{6}$. Está localizado a $14 \mathrm{~km}$ do município de São João del-Rei e a $4 \mathrm{~km}$ do distrito do Rio das Mortes. Por se tratar de um povoado rural pertencente ao município de São João del-Rei, não há informação precisa sobre o número de habitantes do local ${ }^{7}$. Diante da ausência desse tipo de informação, até mesmo pela Prefeitura Municipal de São João del-Rei, foi possível obter apenas o número de eleitores, sendo 292, no ano de 2009, e o número de famílias, 113, que foi contabilizado por uma das moradoras do povoado.

O povoado se divide em quatro regiões: Entrada das Goiabeiras, Goiabeiras de Baixo, Goiabeiras do Meio e Goiabeiras de Cima ou Horta Velha. Tais denominações caracterizam o relevo de planalto da região. A área central do povoado está localizada na região de Goiabeiras de Baixo. É nessa região que se encontra a Escola Municipal de Goiabeiras, a "venda" (que funciona ora como botequim, ora como mercearia), a Conferência São Judas Tadeu (local onde os católicos se reúnem para tratar de assuntos religiosos), o Cruzeiro (um marco com uma cruz de madeira: à sua volta, os fiéis têm o costume de rezar o terço), o telefone público e a capela, que foi construída pelos próprios moradores. $\mathrm{Na}$ Entrada das Goiabeiras, há uma lagoa, onde foi instalado um "pesquepague".

À exceção de algumas famílias que residem em regiões um pouco mais afastadas, onde também se localizam alguns sítios, as residências, na maioria, se encontram próximas umas das outras. As casas são simples, muitas ladeadas com cerca de bambu ou arame farpado. É possível encontrar também algumas construções mais contemporâneas, ainda que em número reduzido, na rua principal do povoado. A maioria das casas possui quintal, sendo comum a criação de galinhas e a plantação de hortaliças, como couve, cebolinha, mandioca etc., além da pre- 
sença de cachorros. Já as famílias que residem em sítios ou em terrenos maiores criam gado e se ocupam com a agricultura (CAMPOS; PORTES, 2006).

No que se refere à rotina dos moradores, em um primeiro contato com o local, tem-se a impressão de que o dia a dia gira em torno do trabalho, do cuidado com os filhos e da interação entre os moradores. Porém, trata-se de uma visão imediata e simplista de uma moradora urbana, pois, à medida que fui me aproximando dos moradores e acompanhando o cotidiano das famílias, pude perceber que existem algumas opções de lazer no povoado e região, como festividades religiosas, aulas de catecismo e de teatro, festas na escola municipal, comemoração de aniversários, realização de casamentos, partidas de futebol entre os times da região, disputas de pelada ${ }^{8}$ no campinho de futebol, bailes, etc.

Na maioria das famílias, são os homens que exercem atividades remuneradas fora do povoado, enquanto as mulheres cuidam dos filhos e dos afazeres domésticos. No final da tarde, os moradores têm o costume de prosear com seus vizinhos nas calçadas ou nas portas de suas residências. Durante a noite, o povoado fica praticamente deserto, com as famílias recolhidas às suas casas. O principal atrativo são os programas televisivos, mormente as telenovelas.

Já os finais de semana giram em torno das visitas às residências dos parentes, almoço em família, partidas de futebol, missas e passeios no pesque-pague. Um lugar de encontro, para os homens, é a venda, onde tomam cerveja enquanto jogam sinuca ou baralho. Entre as opções de entretenimento, o pesque-pague vem se tornando o principal atrativo dos moradores, principalmente para os jovens. Além da pescaria, o espaço oferece área de lazer para as crianças, bar e piscina, além de músicas ao vivo nas tardes de domingo.

Em relação às atividades remuneradas exercidas pelos moradores, é importante ressaltar a existência de um pequeno parque industrial próximo ao povoado. Ele é formado por quatro metalúrgicas, uma extrativa de eucalipto e uma mineração de calcário calcítico. Não são poucos os moradores que ali trabalham, principalmente os homens. A implantação dessas empresas na região é vista de forma positiva por todos, pois, com a escassez de trabalho no local, os homens se empregavam, principalmente, no ramo da construção civil, em empresas das grandes metrópoles, deixando as mulheres e os filhos no povoado. Muitas dessas mulhe- 
res ainda se recordam do tempo em que criavam os filhos sozinhas e se encontravam com o marido uma ou duas vezes por mês.

A maioria dos homens se ocupa de atividades ligadas à indústria civil (pedreiro, armador, carpinteiro, etc.) ou a outros tipos de indústrias (operador de moinho, metalúrgico, auxiliar de serviços gerais, etc.). Poucas mulheres exercem atividade remunerada fora de suas casas. A maioria das que trabalham em São João del-Rei presta serviços como domésticas ou faxineiras. Outras trabalham como lavadeiras, o que as obriga a se deslocarem semanalmente até São João del-Rei para entregar as roupas lavadas e trazer as roupas sujas. É comum também, entre as mulheres, a venda de produtos de catálogos, como perfumes, cremes, batons, materiais para o lar, roupas, etc.

Para o deslocamento dos moradores até São João del-Rei, há uma linha de ônibus que circula diariamente no povoado, nos períodos da manhã, tarde e noite. Entretanto, até há cinco anos, não havia ônibus adentrando o povoado, o que obrigava os moradores a se deslocarem até a Rodovia BR-265, próxima ao povoado, para utilizar linhas de ônibus que tivessem como destino a cidade de São João del-Rei.

Quanto aos serviços básicos de segurança pública e saúde, os moradores têm de se dirigir ao distrito do Rio das Mortes, onde estão localizados o posto policial e o posto de saúde. Como esse posto de saúde possui poucos recursos, além de não contar com um médico plantonista, na maioria dos casos os moradores se deslocam até São João del-Rei. No que se refere a saneamento básico, não existe rede de tratamento de água e esgoto. O povoado é atendido por serviços de luz elétrica e telefonia móvel. A maioria das residências tem instalada antena parabólica, haja vista que sem esse equipamento não seria possível a recepção de sinais de televisão, em função da distância da torre transmissora, que se localiza em São João del-Rei.

No que se refere à escolarização dos moradores do povoado, a Escola Municipal de Goiabeiras e a Escola Estadual Evandro Ávila, essa última localizada no distrito do Rio das Mortes, atendem aos alunos da região. A primeira oferece educação infantil e os cinco primeiros anos do Ensino Fundamental, enquanto a segunda oferece os anos finais do Ensino Fundamental e o Ensino Médio.

Quanto à realização da pesquisa, efetuei uma investigação em moldes etnográficos que me possibilitou recolher detalhes minuciosos 
referentes à rotina das famílias pesquisadas e, assim, produzir um perfil dos estilos de educação de cada uma delas. A pesquisa foi realizada com um grupo de seis famílias: duas negras, duas mestiças e duas brancas. Em cada um desses três subgrupos, a prioridade era selecionar uma família cujos filhos estivessem em idade escolar regular e outra em que os filhos apresentassem defasagem, considerando-se como defasadas aquelas crianças com, no mínimo, dois anos de atraso escolar.

No entanto, com o desenrolar do trabalho de campo, deparei-me com um dado que, inicialmente, configurou-se como obstáculo para o desenho da pesquisa ${ }^{9}$. Após trabalhar com famílias negras e mestiças que possuíam filhos em defasagem escolar, não identifiquei família branca que apresentasse filhos na mesma situação. Assim, optei por trabalhar com uma família branca cuja filha fora reprovada no segundo ano do ensino fundamental. Ou seja, não se trata do mesmo tipo de defasagem apresentado pelas crianças pertencentes às famílias negras e mestiças, mas sim uma defasagem branda ${ }^{10} \mathrm{em}$ virtude de uma única retenção.

Realizar um estudo comparativo foi a forma encontrada para conferir inteligibilidade à pesquisa sobre as famílias negras, pois pouco adianta conhecer uma realidade sem poder contrastar com outra. Assim, ao trabalhar com as famílias brancas e mestiças, pude comparar as práticas empreendidas por elas em relação às famílias negras e verificar se a questão racial influencia ou não tais práticas. Creio que um estudo dessa natureza seria de menor interesse se não fosse levado em consideração o aspecto comparativo e relacional.

A classificação das famílias como negras, mestiças e brancas foi por mim realizada considerando apenas o quesito cor da pele. Para tanto, utilizei as categorias de cor adotadas pelo Instituto Brasileiro de Geografia e Estatística (IBGE): preta, branca, amarela, parda e indígena. Vale mencionar que considerei como famílias negras aquelas em que pais e filhos foram classificados como pretos; como famílias mestiças, aquelas que são fruto de uniões inter-raciais, ou seja, pai preto, mãe branca (ou vice-versa) e filhos pardos; como família branca, aquelas que pais e filhos foram classificados como brancos. De acordo com Osório (2003), classifiquei essas famílias a partir de uma "heteroatribuição", que diz respeito a uma classificação feita por outra pessoa, no caso, a pesquisadora.

A opção por considerar apenas a cor da pele se deve a dois motivos. O primeiro se refere ao fato de o preconceito racial no Brasil ser um 
"preconceito de marca", como bem aponta Nogueira (1998). No Brasil, a cor da pele é um dos quesitos mais utilizados para identificar uma pessoa como negra ou branca. Já o segundo se deve ao alto grau de mestiçagem da população brasileira. Dessa forma, ao se pensar nas famílias do povoado, seria quase impossível encontrar pessoas de cor branca do ponto de vista de uma raça pura, pois os moradores de Goiabeiras são herdeiros de um passado de exploração do ouro e consequente trabalho escravo" ${ }^{11}$.

Os dados referentes às famílias foram obtidos por meio do acompanhamento sistemático da rotina delas. Cada família me recebeu em sua casa durante uma semana. Iniciava o trabalho às segundas-feiras e o concluía aos domingos. Quando possível, pernoitava em alguma residência. Quando não, permanecia em suas casas até o anoitecer ou até o momento em que elas se preparavam para se recolher para dormir.

Concluída a etapa do trabalho junto às famílias, entrevistei as professoras de todas as crianças em idade escolar, o que equivale a um universo de 12 alunos. Essas entrevistas continham apenas duas questões. $\mathrm{Na}$ primeira, a professora (não me deparei com nenhum profissional do sexo masculino) era questionada sobre o modo como ela percebia a participação dos pais daquele aluno no que se referia às atividades escolares (participação em reuniões, festividades promovidas pela escola, comprometimento com o processo de escolarização dos filhos, etc.). Na segunda, a profissional deveria falar do aluno em sala de aula (comportamento disciplinar, acompanhamento dos conteúdos, interação entre pares, entre outros aspectos).

Ao estudar cada uma das seis famílias, seis eixos temáticos foram levados em consideração: (i) Caracterização sociocultural; (ii) Cotidiano da família; (iii) Redes de relações; (iv) Percepção racial; (v) Vínculo com a vida escolar dos filhos; (vi) Família e escola: o que pensam uns dos outros?

Cabe mencionar que a escolha desses eixos resultou da análise da empiria e do diálogo com autores do campo da Sociologia da Educação que tiveram como foco o processo de escolarização de famílias urbanas, sendo a maioria dessas famílias pertencente aos meios populares (CLARK, 1983; LAHIRE, 2008; LAREAU, 2007; PORTES, 2000; THIN, 2006; VIANA, 2000). Cada um dos eixos abordados nos permite compreender como alguns fatores socioeconômicos e culturais (capital escolar da família estendida, tipos de interação entre os familiares, condições materiais de existência, profissão dos pais, religiosidade, trajetória de vida 
da família, ordenamento dos lares, controle dos pais sobre os filhos, etc.) estão relacionados, explícita e implicitamente, às práticas de escolarização empreendidas pelos pais das famílias negras, mestiças e brancas.

\section{Alguns resultados e considerações sobre as práticas de escolarização das famílias pesquisadas}

Partindo da leitura de estudos sobre desigualdades raciais e educação, trabalhei com a hipótese de que os itinerários escolares dos filhos de familias negras seriam mais acidentados do que os das famílias brancas e mestiças. No entanto, os resultados obtidos não confirmaram minha hipótese de trabalho. Eles mostraram que as práticas de escolarização empreendidas pelas famílias pesquisadas não se diferenciam segundo o pertencimento racial. Assim, encontrei crianças com trajetórias regulares de escolarização em uma família negra, em uma família mestiça e em uma família branca. Além disso, são essas famílias que adotam práticas sistematizadas, no sentido de garantir bom desempenho dos filhos na escola, visando a um caminho de longevidade escolar. Se a raça não contribuiu para explicar diferenças no processo de escolarização, que outros fatores poderiam contribuir para ajudar na compreensão das diferenças de itinerários e nas práticas empreendidas?

A análise do material coletado apontou, primeiramente, para dimensões relativas a um conjunto de circunstâncias atuantes ${ }^{12}$ presentes nas famílias cujos filhos apresentam itinerários regulares e que exercem práticas de escolarização sistematizadas. Chamarei essas famílias de Grupo 1, o qual é composto por uma família negra, uma mestiça e uma branca. As demais famílias, ou seja, aquelas que apresentam filhos com defasagem escolar e certo afrouxamento no que diz respeito ao acompanhamento da vida escolar dos filhos, chamarei de de Grupo 2, também composto por uma família negra, uma mestiça e uma branca.

Segundo Portes (2000, p. 65), esses conjuntos de circunstâncias atuantes

[...] se combinam entre si e só fazem sentido se inseridas "na rede de seus entrelaçamentos concretos" (LAHIRE, 1997:72), sendo que não parecem possuir efeito importante de forma isolada. Elas atuam no decorrer da trajetória, diante das necessidades e questionamentos cotidianos a serem enfrentados pela família. 
Esse conjunto de circunstâncias atuantes, além de influenciar as práticas de escolarização das famílias, atua também de forma positiva no processo de escolarização dos filhos. Essa afirmação é possível devido ao fato de os filhos que se encontram em idade escolar regular pertencerem ao Grupo 1, ou seja, pais que apresentam alta mobilização em relação à vida escolar dos filhos (Quadro 1).

QUADRO 1. Situação escolar dos filhos segundo o tipo de acompanhamento os pais no processo de escolarização e pertencimento racial das famílias

\begin{tabular}{c|c|c}
$\begin{array}{c}\text { Tipo de Acompanhamento dos Pais no } \\
\text { Processo de Escolarização dos Filhos }\end{array}$ & Pertencimento Racial & Situação Escolar dos Filhos \\
\hline Forte & Família Negra (Família 1) & Idade regular \\
Forte & Família Mestiça (Família 3) & Idade regular \\
Forte & Família Branca (Família 5) & Idade regular \\
Fraco & Família Negra (Família 2) & Defasagem escolar \\
Fraco & Família Mestiça (Família 4) & Defasagem escolar \\
Fraco & Família Branca (Família 6) & Defasagem branda
\end{tabular}

O conjunto de circunstâncias mencionadas a seguir apresenta algumas aproximações de acordo com a temática abordada. Assim, para melhor organização do texto e compreensão do leitor, elas foram divididas em quatro categorias: Condições socioeconômicas da família; Níveis de escolarização dos membros das famílias; Relações sociais entre membros da família e da família com outras pessoas; Modo como a família conduz o processo de escolarização dos filhos.

\section{a) Condições socioeconômicas da família}

Os pais pertencentes ao Grupo 1 não sofreram, no período da infância, com a ausência significativa de recursos econômicos e materiais em seus lares, não lhes sendo necessário exercer, na época, qualquer tipo de atividade remunerada. Ainda que passassem por dificuldades financeiras que os impedia de prosseguir os estudos em São João del-Rei, após o término da quarta série, elas existiram em menores proporções, se considerarmos as famílias do Grupo 2. Nesse último, tanto as mães quanto os pais começaram a trabalhar ainda crianças para ajudar nas despesas da casa. Não me refiro aqui às atividades em que os filhos auxiliavam os pais (serviços na roça e trabalhos domésticos), mas, sim, atividades que exigem 
esforço físico maior (babá, baldeira ${ }^{13}$, lavrador, entre outras). Ademais, os pais do Grupo 1 cresceram em companhia de seus pais e irmãos, ou seja, da família nuclear, não sendo entregues aos cuidados de parentes ou pessoas externas à rede familiar, em virtude de dificuldades financeiras, como aconteceu com algumas famílias do Grupo 2.

As famílias do Grupo 1 contam com uma fonte de ajuda financeira, à qual podem recorrer diante de gastos inesperados (doença, desemprego, viagem, etc.). Esse apoio lhes permite certa organização e estabilidade nos gastos e despesas familiares. Um indicador importante para se compreender o modo como os pais do Grupo 1 lidam com o processo de escolarização de seus filhos é o fato de essas famílias disporem de recursos econômicos necessários que lhes garantem uma rotina estável e tranquila nos lares.

Aliás, a renda das famílias também aparece como uma circunstância importante de ser analisada. As famílias do Grupo 1 apresentam renda mensal superior a dois salários mínimos, o que não ocorre nas famílias pertencentes ao Grupo 2. Em um primeiro momento, essa variação salarial entre as famílias de ambos os grupos pode não parecer significativa, mas se considerarmos as necessidades materiais e os gastos mensais de cada uma delas, fica evidente que se trata de uma diferença pertinente.

Essa elevação registrada no Grupo 1 permite que os filhos dessas famílias desfrutem de melhor ordenamento dos lares verificado nos móveis da residência (novos ou conservados), na posse de equipamentos e serviços, na estrutura física das casas, etc. Além disso, a compra de materiais escolares, uniformes e satisfação de outras necessidades relativas à escolarização dos filhos se encaixam nas despesas da família, sem causar grandes desequilíbrios orçamentários.

\section{b) Níveis de escolarização dos membros das famílias}

Existe uma elevação no que se refere ao capital escolar dos pais, tios e avós das famílias do Grupo 1. Trata-se de famílias em que a maioria dos avós foi escolarizada, tendo alguns deles completado a quarta série, o que não acontece com nenhum dos avós pertencentes ao Grupo 2. Em relação aos membros da segunda geração (os tios e pais das crianças), há também uma elevação do nível de escolaridade se comparado às famílias do Grupo 2. No Grupo 1, todos os membros concluíram a quarta série. 
A conclusão do segundo grau (atual Ensino Médio) é registrada tanto entre a família paterna quanto materna. Além disso, entre alguns membros dessas famílias, a formação de nível superior foi concretizada, por meio, inclusive, do ingresso em uma instituição federal (Universidade Federal de São João del-Rei). Entretanto, se considerarmos esses dados entre os membros das famílias do Grupo 2, depararemo-nos com a ausência de formação de nível médio e superior.

Considerando que o capital escolar dos pais do Grupo 1 é mais elevado, compreende-se o fato de eles lidarem com o processo de escolarização de seus filhos de maneira direta, sistemática e sem grandes conflitos, uma vez que conhecem, minimamente, a estrutura e o funcionamento da escola. Entretanto, ao apontar os efeitos positivos do capital escolar nas famílias do Grupo 1, uma vez que os filhos se encontram em idade escolar regular, é relevante mencionar que não se trata de um processo determinista. O capital escolar da família se revela como fator importante no processo de escolarização dos filhos, mas não é o único. Pode-se dizer que ele apresenta suas contribuições combinado com outras variáveis, como o tipo de relação que a família estabelece com a criança desde o início de sua vida escolar. Para Lahire (2008, p. 338), “a presença objetiva de um capital cultural familiar só tem sentido se esse capital cultural for colocado em condições que torne possível sua "transmissão"'.

Cabe destacar também que os pais do Grupo 1 não sofreram reprovações e guardam boas lembranças do ambiente escolar. "[...] Era uma maravilha. [...] a gente era muito feliz, feliz demais". Nosso professor era muito legal" (fala de uma das mães entrevistadas do Grupo 1). Não sendo, para esses pais, a socialização escolar marcada por rupturas e descontentamentos, a relação que eles estabelecem com o processo de escolarização de seus filhos traz os reflexos positivos dessa época: “[...] do ponto de vista da escolaridade da criança, é sem dúvida preferível ter pais sem capital escolar a ter pais que tenham sofrido na escola e que dela conservem angústias, vergonhas, complexos, remorsos, traumas ou bloqueios" (LAHIRE, 2008, p. 344-345).

Já em relação ao percurso escolar dos pais pertencentes ao Grupo 2, é possível destacar alguns fatores que influenciaram de forma negativa suas trajetórias, levando até mesmo alguns deles a abandonarem a escola, tais como: a morte repentina de um ente querido, expulsões e 
transferências de escola, vítima de insultos dos colegas, problemas de saúde, falta de assiduidade às aulas, entre outros.

A maioria dos pais do Grupo 1 alimentava o desejo de prosseguir os estudos; no entanto, tiveram suas trajetórias interrompidas, uma vez que a quinta série só era oferecida em escolas da rede privada, na cidade de São João del-Rei.

Eu chorei muito o dia que acabou, porque aí meus pais não deixou eu estudar mais, n/é? Sofri pra caramba [...]. Eu chorei muito quando saí da escola. [...] Nossa, eu fiquei inconformada, porque eu sabia que eu ia virar uma profissional bacana. (fala de uma das mães entrevistadas do Grupo 1)

Esse desejo interrompido dos pais vem sendo projetado nos filhos, pois a permanência destes na escola e o alongamento do percurso escolar representam, para eles, de certa forma, uma realização pessoal negada no passado.

\section{c) Relaç̃ões sociais entre membros da família e da família com outras pessoas}

Nas famílias do Grupo 1, o diálogo entre pais e filhos é bem mais frequente. Gritos e xingamentos raramente são utilizados quando as crianças apresentam comportamentos e atitudes reprovados pelos pais. Nessas situações, mesmo que os pais se utilizem de castigos de ordem privativa (impedem as crianças de assistir a programas de televisão, participar de passeios, brincar com colegas, etc.), os argumentos de defesa apresentados pelos filhos são sempre ouvidos. Vale mencionar que Montandon (1991) e Lareau (2008) também se depararam com esse tipo de relação ao analisarem o modo como os pais lidam com o processo de escolarização dos filhos. Montandon (1991) verifica que, entre as famílias que apresentam forte estimulação extraescolar, há também forte comunicação entre o casal e os filhos. Ela denomina o estilo educativo dessas famílias de "style contractualiste".

Nas famílias do Grupo 1, os pais também demonstram maior envolvimento e atenção ao escutar as histórias e os relatos dos filhos. Palavras e gestos carinhosos, além do respeito mútuo, são comuns entre eles. Os filhos não têm o hábito de responder mal aos pais ou de alterar o tom de voz ao receberem uma advertência. Não há, também, diferenciação entre a autoridade exercida pelo pai ou pela mãe: ambos apresen- 
tam certa autonomia quando precisam proibir ou tomar alguma decisão cujos interessados são os filhos.

Já nas famílias do Grupo 2, é sempre o pai quem exerce maior autoridade sobre os filhos e quem dá a palavra final. Aqueles que geralmente têm o hábito de responder grosseiramente à mãe, principalmente quando são contrariados, dificilmente o fazem quando estão interagindo com a figura paterna. Acrescente-se a relação estabelecida entre os irmãos. Ainda que desentendimentos não estejam ausentes no Grupo 1, estes não vão além de algumas discussões verbais. Ao passo que os filhos do Grupo 2 acabam, muitas vezes, revidando com agressões físicas (arremesso de chinelos, beliscões, chutes na canela, pontapés, tapas, etc.).

No Grupo 1, as esposas e os maridos estabelecem diálogos constantes, trocam ideias, opiniões, acompanham juntos os gastos da família, fazem planos futuros e dividem problemas. É comum também encontrá-los juntos nas festas do povoado, missas e eventos na escola de Goiabeiras. O que não acontece com frequência entre as famílias do outro grupo, ou seja, se no Grupo 1 os casais estabelecem uma relação estreita, amigável e, em alguns momentos, amorosa, no Grupo 2, esse tipo de relação não é tão próxima assim.

Além disso, entre os casais pertencentes ao Grupo 1, pode-se dizer que não existe delimitação de papéis no que se refere aos serviços domésticos, os quais são desempenhados, majoritariamente, pelas mães e pelas filhas no Grupo 2. Os maridos do Grupo 1 auxiliam com frequência suas esposas nas tarefas diárias, lavar louças, preparar o almoço ou o jantar, cuidam dos filhos, entre outras tarefas.

Nas famílias do Grupo 1 também existe controle maior dos pais em relação à rotina dos filhos. As atividades diárias na casa são bem-estruturadas, ocorrendo quase sempre no mesmo horário: cumprimento dos deveres escolares, auxílio aos pais nos serviços da casa, brincadeiras, assistir à televisão, etc. Os casais também se preocupam em manter os filhos sempre perto de casa, controlam suas redes de amizade e ficam apreensivos quando eles demoram a chegar da escola, do catecismo, das aulas de teatro, entre outros eventos, em virtude dos quais se deslocam no povoado sem a companhia dos pais. No Grupo 2, a rotina dos filhos é menos ordenada pelos pais. A expressão "eles que comandam eles mesmos", utilizada por uma profissional da escola de Goiabeiras, descreve, em parte, o dia a dia dessas crianças e adolescentes. 
Outra circunstância verificada nas famílias do Grupo 1 e que se relaciona às interações cotidianas estabelecidas entre os seus membros diz respeito à intensidade do envolvimento das famílias com as práticas de cunho religioso. Embora todas as famílias pesquisadas sejam católicas atuantes, uma vez que fazem suas orações, assistem às missas, os filhos participam de cursos de catecismo e crisma, no Grupo 1, o envolvimento com as atividades da igreja, principalmente por parte das mães, é maior.

No Grupo 1, registra-se, ainda, outra circunstância que se refere às redes de relações externas ao povoado. Essas famílias mantêm ligação mais efetiva com moradores de São João del-Rei, uma vez que o deslocamento delas entre Goiabeiras e a cidade é maior. No que se refere às famílias do Grupo 2, as relações externas ao povoado são reduzidas. Estas se resumem, basicamente, a algumas idas a São João del-Rei para pagamentos de contas, compras, serviços de saúde, serviços bancários, entre outros não oferecidos no povoado e no distrito do Rio das Mortes. No entanto, é importante destacar que essas relações externas ao povoado, mantidas com maior frequência entre as famílias do Grupo 1, contribuem para a ampliação de seus horizontes, o que se relaciona às aspirações dos pais em relação ao futuro dos filhos.

\section{d) Modo como a família conduz o processo de escolarização dos filhos}

Nas entrevistas realizadas com as professoras, foi possível perceber que existe uma oscilação entre um grupo de pais que as profissionais julgam acompanhar de perto a vida escolar dos filhos e outro grupo que se encontra mais distante desse tipo de acompanhamento. De acordo com a fala das professoras, as famílias do Grupo 1 se encaixam no primeiro grupo. Ao passo que as famílias do Grupo 2 se encaixam no segundo grupo, em que os pais não se envolvem diretamente com o processo de escolarização dos filhos: Algumas frases utilizadas pelas profissionais entrevistadas evidenciam o modo como elas percebem o envolvimento dos pais dos dois grupos:

\section{Grupo 1:}

[...] a família acompanha muito (Família Negra).

[...] muito interessada no desenvolvimento escolar do filho. Disponível para qualquer coisa (Família Mestiça).

[...] um tipo de família que a gente gostaria de ter (Família Branca). 


\section{Grupo 2:}

[...] Eu acho que em casa ele não tem acompanhamento nenhum (Família Negra).

[...] Eu não sinto muito envolvimento não (Família Mestiça).

[...] nunca conversei diretamente, assim, sozinha, com os pais dela não (Família Branca).

Para o sociólogo Pedro Silva, a imagem que os professores criam a respeito das famílias está diretamente ligada à imagem de seus alunos: "[...] Os bons pais tendem a sê-lo dos bons alunos [...] Estranho? Nem tanto. Círculo Vicioso? Sim" (SILVA, 2003, p. 344, grifo do autor). Thin (2006) também aponta para essa relação, pois os professores criam, através de uma série de comportamentos apresentados pelos alunos (tipos de vestuário, adesão às regras, atenção, desatenção, etc.), uma representação acerca das práticas e do modo de vida das famílias.

Em relação ao sentido da escola para a vida dos filhos, a grande maioria dos pais, tanto no Grupo 1 quanto no Grupo 2, concebe a escolarização sob a ótica instrumental ${ }^{14}$. No entanto, existe uma variação quanto ao nível das expectativas. Os pais do Grupo 1 esperam que os filhos tenham um percurso escolar de longa duração, com acesso ao ensino superior. Eles falam naturalmente dessa possibilidade, não demonstrando certo distanciamento, como os pais do Grupo 2.

Além disso, os pais pertencentes ao Grupo 1 demonstram estar dispostos a ajudar os filhos no que for preciso e no que estiver ao alcance da família, principalmente em se tratando de recursos econômicos. A frase utilizada por um dos pais desse grupo ilustra esse tipo de incentivo: "O que eu puder fazer pra eles, eu faço mesmo. Eu não tenho dificuldade, não". Já as aspirações dos pais pertencentes ao Grupo 2 são mais moderadas; por exemplo, a formação de nível superior raramente foi citada por esses pais.

Contudo, as famílias de ambos os grupos concebem a escola como algo importante para a vida dos filhos. Mesmo que no Grupo 2 existam dissonâncias entre os modos de socialização escolar e familiar (PAIXÃO, 2006) e que frequentemente os pais vivenciem situações conflituosas por não compreenderem as regras do sistema escolar, as famílias reconhecem o valor simbólico da escola.

Embora atribuam valor considerável ao processo de escolarização dos filhos, as práticas empreendidas por elas, no sentido de garantir a 
permanência e o prolongamento da trajetória escolar dos filhos, apresentam variações entre os pais dos Grupos 1 e 2 . No primeiro, os pais empreendem o controle sistemático na vida escolar dos filhos, acompanham de perto seus resultados e atividades escolares. Já os pais do segundo grupo apresentam certo afrouxamento nesse tipo de acompanhamento e não empreendem práticas tão elaboradas quanto os do primeiro.

Além das quatro categorias de circunstâncias atuantes aqui apresentadas vale destacar que a análise do material coletado demonstrou (como era esperado) que as crianças que se encontram em idade escolar regular pertencem, justamente, a famílias que apresentam comportamentos valorizados pela escola, independentemente do pertencimento racial de cada uma delas. Por exemplo, esses pais, entre outros fatores:

1. acompanham diariamente a vida escolar dos filhos;

2. estabelecem horários para que estes cumpram os deveres e trabalhos escolares;

3. detêm maior controle sobre os filhos;

4. apresentam uma rotina no interior dos lares;

5. são assíduos às reuniões de pais;

6. mantêm contato mais próximo com a equipe pedagógica da escola.

Se minha hipótese inicial era a de que a questão racial pudesse exercer influência sobre as práticas de escolarização empreendidas pelos pais, as análises aqui realizadas me levam a afirmar que estas não se diferenciaram segundo o pertencimento racial, uma vez que temos famílias negra, mestiça e branca que adotam práticas sistematizadas no sentido de garantir o bom desempenho dos filhos na escola, visando, inclusive, a um caminho de longevidade escolar. Como vimos, as práticas se diferenciam de acordo com uma série de circunstâncias atuantes presentes em maiores proporções nas famílias do Grupo 1, as quais só puderam ser compreendidas e ganharam sentido ao cruzarmos as informações referentes às seis famílias pesquisadas.

Entretanto, estudos conhecidos sobre desigualdades raciais no Brasil apontam, a partir de dados estatísticos, que há desigualdades econômicas e educacionais entre brancos e negros (ALVES, et al., 2007; GARCIA, 2007; HENRIQUES, 2002; HERINGER, 2002; SOARES; ALVES, 2003). $\mathrm{E}$ os dados coletados por mim desmentem os resultados dessas pesquisas? 
De certa forma, é possível dizer que não. Tais desigualdades emergem de forma sutil, por exemplo, quando constato que não há, no povoado, família branca cujos filhos estivessem em situação de defasagem escolar. Ou quando se verifica ser uma família negra que se encontra em piores condições materiais de existência, com maior número de filhos, frente a outras famílias de Goiabeiras, além do baixo desempenho escolar apresentado por eles, desde o mais velho até o caçula.

Vale ressaltar que esta pesquisa apresenta detalhes minuciosos da vida das famílias, o que nos permite compreender como determinadas circunstâncias presentes no cotidiano de cada uma delas refletem de maneira positiva e negativa na vida escolar dos filhos. Em contrapartida, o tipo de metodologia adotada (pesquisa participativa com características etnográficas) não me permitiu trabalhar com um número maior de famílias. Nesse sentido, não tenho condições de proceder a generalizações a respeito dos resultados obtidos. Afirmar que a questão racial não apresentou influências nas práticas de escolarização empreendidas pelas seis famílias pesquisadas não é o mesmo que dizer que a questão racial não influencia nas práticas de escolarização empreendidas por todas as famílias de Goiabeiras que possuem filhos em idade escolar. Penso que a realização de pesquisas nos moldes aqui adotados, porém realizadas em outros locais e contextos, só tem a contribuir com a temática pesquisada, pois assim será possível estabelecer analogias e semelhanças entre o estudo aqui empreendido. Acrescente-se a ausência de pesquisas no Brasil, principalmente no campo da Sociologia da Educação, que tomem como foco as práticas de escolarização das famílias, levando em consideração a questão racial. 


\section{Referências}

ALMEIDA, W. M. Estudantes com desvantagens econômicas e educacionais e fruição da universidade. Cadernos CRH, Salvador, v. 20, n. 49, p. 35-46, 2007.

ALVES, F.; FRANCO, C.; ORTIGÃO, I. Origem social e risco de repetência: interação raça-capital econômico. Cadernos de Pesquisa, São Paulo, v. 37, n. 130, p. 161-180, jan./abr. 2007.

BOURDIEU, P. Os três estados do capital cultural. In: NOGUEIRA, M. A.; CATANI, A. (Orgs.). Escritos de educação. Petrópolis: Vozes, 1998, p. 71-79.

BRESSOUX, P. As pesquisas sobre o efeito-escola e o efeito-professor. Educação em Revista: revista da Faculdade de Educação da UFMG, Belo Horizonte, n. 38, p. 17-88, 2003.

CAMPOS, A. R. As práticas de escolarização de famílias rurais: um estudo comparativo entre famílias negras, mestiças e brancas do povoado de Goiabeiras, São João del-Rei, MG. 2010. 187 f. Dissertação (Mestrado em Educação) - Niterói, Universidade Federal Fluminense, 2010.

CAMPOS, A. R.; PORTES, É. A. O perfil de famílias rurais do povoado de Goiabeiras com filhos em idade escolar, São João del-Rei, Minas Gerais. In: SEMINÁRIO DE INICIAÇÃO CIENTÍFICA, 14., 2006, São João del-Rei. Anais... São João del-Rei: UFSJ / CONGRESSO DE PRODUÇÃO CIENTÍfICA DA UFSJ, 5., São João del-Rei, 2006. Anais... São João del-Rei: UFSJ, 2006.

CHARLOT, B. Da relação com o saber: elementos para uma teoria. Trad. Bruno Magne. Porto Alegre: ARTMED, 2000.

CLARK, R. M. Family life and school achievement: why poor black children succeed or fail. Chicago: The University of Chicago Press, 1983.

GARCIA, R. C. Identidade fragmentada: um estudo sobre a história do negro na educação brasileira - 1993-2005. Brasília: Instituto Nacional de Estudos e Pesquisas Educacionais Anísio Teixeira, 2007.

GOMES, J. B. B. Ação afirmativa \& princípio constitucional da igualdade: o Direito como princípio de transformação social; a experiência dos EUA. Rio de Janeiro: Renovar, 2001.

GUERRA, A.; OLIVEIRA, E. H.; SANTOS, M. Estrada Real: análise crítica das políticas de exploração turística da estrada Real adotadas pelo governo do estado de Minas Gerais no período de 1999 a 2003. 2003. 56 f. Monografia (Especialização em Turismo e Desenvolvimento Sustentável) - Belo Horizonte, Instituto de Geociências da Universidade Federal de Minas Gerais, 2003.

HENRIQUES, R. Raça e gênero no sistema de ensino: os limites das políticas universalistas na educação. Brasília: Unesco, 2002.

HERINGER, R. Desigualdades raciais no Brasil: síntese de indicadores e desafios no campo das políticas públicas. Cad. Saúde Pública, n. 18 (suplemento), p. 57-65, 2002.

LACERDA, W. M. G. Percursos escolares atípicos: o possível contra o provável. Revista de Ciências Humanas, Viçosa, v. 6, p. 171-196, 2006.

LAHIRE, B. Sucesso escolar nos meios populares: as razões do improvável. São Paulo: Ática, 2008.

LAREAU, A. A desigualdade invisível: o papel da classe social na criação dos filhos em famílias negras e brancas. Educação em Revista, Belo Horizonte, n. 46, p. 13-82, dez., 2007. 
MONTANDON, C. Les stratégies éducatives des familles: milieu social, dynamiques familiales et éducation des pré-adolescents. Paris: Delachaux\&Niestlé, 1991.

NOGUEIRA, O. Preconceito de marca: as relações raciais em Itapetininga. São Paulo: Edusp, 1998.

OSÓRIO, R. G.. O sistema classificatório de cor ou raça do IBGE. Brasília: Instituto de Pesquisa Econômica Aplicada, 2003. (Texto para Discussão, n. 996.)

PAIXÃO, L. P. Escolarização: estratégias instrumentais e identitárias. Atos de Pesquisa em Educaşão, v. 2, n. 1, p. 23-51, jan.-abr. 2007.

PAIXÃO, L. P. Compreendendo a escola na perspectiva das famílias. In: MÜLLER, M. L. R.; PAIXÃO, L. P. Educação, diferenças e desigualdades. Cuiabá: Ed. da FMT, 2006. p. 5781.

PAIXÃO, L. P. Significado da escolarização para um grupo de catadoras de um lixão. Cadernos de Pesquisa, São Paulo, v. 35, n. 124, abr. 2005.

PESQUISA NACIONAL POR AMOSTRA DE DOMICÍLIO. Síntese de Indicadores Sociais 2010. Disponível em: <http://www.ibge.gov.br/home/presidencia/noticias/noticia_visualiza.php?id_noticia=1717\&id_pagina=1>. Acesso em: 10 out. 2010.

PIOTTO, D. C. Trajetórias escolares prolongadas nas camadas populares. Cadernos de Pesquisa, São Paulo, v. 38, n. 135, p. 701-727, set.-dez. 2008.

PORTES, É. A. O trabalho escolar das famílias populares. In: NOGUEIRA, M. A., ROMANELLI, G; ZAGO, N. (Orgs.). Família e escola: trajetórias de escolarização em camadas médias e populares. Petrópolis: Vozes, 2000. p. 63-80.

RETRATO DAS DESIGUALDADES DE GÊNERO E RAÇA. Luana Pinheiro et al. 3 ed. Brasília: IPEA: SPM: UNIFEM, 2008. 36 p.: gráficos, tabelas. Inclui CD-ROM e um cartaz. Disponível em:

<www.ipea.gov.br/sites/000/2/destaque/Pesquisa_Retrato_das_Desigualdades.pdf $>$. Acesso em: 10 out. 2008.

SILVA, P. Escola-família, uma relação armadilhada: interculturalidade e relações de poder. Porto: Afrontamento, 2003.

SOARES, J. F.; ALVES, M. T. Desigualdades raciais no sistema brasileiro de educação básica. Educação e Pesquisa, São Paulo, v. 29, p. 147-165, 2003.

THIN, D. A. D. Famílias de camadas populares e a escola: confrontação desigual e modos de socialização. In: MÜLLER, M. L. R.; PAIXÃO, L. P. (Orgs.). Educação, diferenças e desigualdades. Cuiabá: EDUFMT, 2006. p. 17-55.

VIANA, M. J. B. Longevidade escolar em famílias de camadas populares: algumas condições de possibilidade. In: NOGUEIRA, M. A., ROMANELLI, G; ZAGO, N. (Orgs.). Família e escola: trajetórias de escolarização em camadas médias e populares. Petrópolis: Vozes, 2000. p. 47-60. 


\section{Notas}

1 A referida dissertação foi defendida em março de 2010, no Programa de PósGraduação em Educação, pela Universidade Federal Fluminense, tendo como orientadora a Prof . Dr $^{\text {a }}$. Lea Pinheiro Paixão. A pesquisa contou com o apoio financeiro do Conselho Nacional de Desenvolvimento Científico e Tecnológico - CNPq.

2 De acordo com Portes (2000), entende-se por práticas de escolarização todas aquelas ações - ocasionais ou precariamente organizadas - empreendidas pela família no sentido de assegurar a entrada e a permanência do filho no sistema escolar, de modo a influenciar a trajetória escolar da criança, possibilitando a ela alcançar os níveis mais altos de escolaridade, como, por exemplo, acesso a curso superior.

3 Mais à frente, tratarei da localização geográfica e de características gerais do povoado de Goiabeiras.

4 Essa pesquisa foi realizada no período de 2005-2008, sob orientação do Prof. Dr. Écio Antônio Portes - Universidade Federal de São João del-Rei (UFSJ).

5 Cabe ressaltar que a questão racial, nos Estados Unidos, se distingue significativamente da realidade brasileira. De acordo com Gomes (2006), os Estados Unidos foram o primeiro país a adotar eficazmente as políticas de ação afirmativa, rompendo inclusive as barreiras da ortodoxia institucional do direito americano.

6 A Estrada Real foi o caminho percorrido por exploradores bandeirantes, principalmente paulistas, em busca de índios e, posteriormente, de ouro e pedras preciosas. A estrada se divide em Caminho Velho, Caminho Novo e Caminho dos Diamantes. O Caminho Velho, tomado por Fernão Dias Paes entre os anos de 1674 a 1681, inicia-se em Paraty (estado do Rio de Janeiro) e segue em direção ao norte do estado de São Paulo. O Caminho Novo foi instituído pela Coroa portuguesa em 1698 e aberto em 1707. Ele liga a região das minas à Baía de Guanabara, iniciando no Rio de Janeiro e terminando em Vila Rica (atual Ouro Preto, MG). E, por último, o Caminho dos Diamantes, estabelecido pela Coroa portuguesa como caminho oficial de Vila Rica a Diamantina. Esse caminho surgiu a partir da descoberta de diamantes em Serro Frio (atual município do Serro, MG), na primeira metade do século XVIII (GUERRA et al., 2003)

7 Os recenseamentos realizados pelo IBGE dispõem somente do número de habitantes da população rural pertencente ao distrito do Rio das Mortes, englobando, assim, não só o povoado de Goiabeiras, como também outros povoados rurais existentes na região.

8 Pelada é o nome dado no Brasil ao jogo de futebol entre amadores, em campo improvisado e sem uniforme. Disponível em: <http://houaiss.uol.com.br/busca.jhtm?verbete $=$ pelada\&cod $=145470>$. Acesso em: 24 jan. 2010.

$9 \mathrm{Na}$ verdade, tratava-se de uma informação de suma importância para os resultados deste estudo.

10 De acordo com Campos e Portes (2006), entende-se por defasagem branda a situação daqueles alunos que, em função do mês de nascimento ou mesmo devido a uma reprovação, não se distanciaram significativamente do ano escolar regular para sua idade. 
11 Para mais informações sobre a história do povoado de Goiabeiras, ver Campos (2010).

12 Esse "conjunto de circunstâncias atuantes" foi denominado por Portes (2000, p. 65) para investigar o trabalho escolar de algumas famílias populares cujos filhos ingressaram em cursos altamente seletivos na Universidade Federal de Minas Gerais (UFMG). O autor aborda seis circunstâncias: a presença da ordem moral doméstica; a atenção com o trabalho escolar do filho; um esforço para compreender e apoiar o filho; a presença do outro na vida do estudante; a busca da ajuda material e a existência e importância de um duradouro grupo de apoio construído no interior do estabelecimento escolar.

13 Expressão utilizada pela filha da família negra pertencente ao Grupo 2 para se referir à atividade em que a avó e a mãe carregavam água em baldes, para encher a caixa d'água das residências de outros moradores.

14 De acordo com Paixão (2007), na lógica instrumental, os ensinamentos escolares podem ser vistos como meio de qualificação profissional, aquisição de um diploma de curso superior, o que, por sua vez, possibilita a elevação da posição social.

Recebido: 20/12/2010

Aprovado: 05/03/2012

Contato:

Avenida Luiz Giarola, 1957

Colônia do Marçal

CEP 36302-260

São João del-Rey, MG

Brasil 